Article

\title{
Research on Model Predictive Control of IPMSM Based on Adaline Neural Network Parameter Identification
}

\author{
Lihui Wang, Guojun Tan * and Jie Meng \\ School of Electrical and Power Engineering, China University of Mining and Technology, Xuzhou 221116, \\ China; ts17130193p3@cumt.edu.cn (L.W.); mengdajie14@163.com (J.M.) \\ * Correspondence: gitan@cumt.edu.cn; Tel.: +86-138-0521-9335
}

Received: 22 October 2019; Accepted: 12 December 2019; Published: 17 December 2019

check for updates

\begin{abstract}
This paper reports the optimal control problem on the interior permanent magnet synchronous motor (IPMSM) systems. The control performance of the traditional model predictive control (MPC) controller is ruined due to the parameter uncertainty and mismatching. In order to solve the problem that the MPC algorithm has a large dependence on system parameters, a method which integrates MPC control method and parameter identification for IPMSM is proposed. In this method, the d-q axis inductances and rotor permanent magnet flux of IPMSM motor are identified by the Adaline neural network algorithm, and then, the identification results are applied to the predictive controller and maximum torque per ampere (MTPA) module. The experimental results show that the optimized MPC control proposed in this paper has a good steady state and robust performance.
\end{abstract}

Keywords: interior permanent magnet synchronous motor (IPMSM); optimal control; model predictive control (MPC); maximum torque per ampere (MTPA); parameter mismatch; parameter identification; Adaline neural network; control performance

\section{Introduction}

IPMSM has been extensively utilized in the fields of electromechanical drives, servo systems, and automotive industry due to its strong reliability, high efficiency, high power density, and a large torque-ampere ratio [1,2]. In order to achieve excellent performance of both dynamic and steady-state current control, many researches focused on the control algorithms of IPMSM, and the most common control algorithms are hysteresis control, proportional-integral (PI) control [3], MPC [4,5], and nonlinear control [6].

Among all these control algorithms, hysteresis control has many advantages such as quick current responses, good robustness, and simple algorithm implementation. However, large current ripple and variable switching frequency are difficult to be avoided. The PI control algorithm has advantages such as high steady-state control precision and fixed switching frequency. However, for PI-based current double closed-loop IPMSM control system, the method of setting PI parameters is too complicated [7,8]. In our case, first, considering the IPMSM double closed-loop control system, which is often regarded as a linear continuous system. The method of numerical analysis and calculation in the continuous domain can be used to adjust the PI parameters, but it requires complex theoretical derivation and mathematical calculation. Second, for the PI controller, although the method of system analysis in the s domain is simple, it needs to be regarded as a continuous module. However, the commonly used PI controllers are digital modules programmed in digital processors analyzed in discrete domain, so only when the sampling frequency is high enough relative to the system working frequency, can IPMSM double closed-loop control system get good control effect. With the development and 
application of microprocessors, new control algorithms have been extensively studied, including predictive control and nonlinear control. Physical systems are inherently nonlinear. Thus, all control systems are nonlinear to a certain extent. Considering the nonlinear characteristics of the system, common nonlinear control strategies such as sliding mode control $[9,10]$, adaptive control $[9,11]$ and intelligent control $[12,13]$ are proposed. These nonlinear control strategies can improve the dynamic and static performance and the robustness of the system in different ways. But at the same time, the above algorithm increases the complexity of the control system without exception, and increases the amount of calculation, which brings obstacles to practical applications. However, if the operating range of a control system is small and the involved nonlinearities are smooth, then the control system can be reasonably approximated by a linearized system. MPC algorithm [14-16] shows a better steady-state and dynamic performance compared to hysteresis control algorithm and PI control algorithm, and its calculation is relatively simpler compared to nonlinear control. MPC has attracted many relevant researchers to conduct their work on it, and its related technology has become a hot research direction.

MPC is gradually applied to power electronic systems because of its fast transient current response, easily modeling and multivariable constraint control capability. The MPC is mainly divided into continuous control set-MPC (CCS-MPC) and discrete state limited control set MPC (FCS-MPC) [17]. The main difference between the two algorithms is whether the control system requires a modulation unit. Compared with CCS-MPC, FCS-MPC does not need pulse width modulation (PWM) modulator, and it does not need to comprehensively consider the prediction time domain, control time domain, and the coordination design of weight coefficients of each time domain objective function. The key of FCS-MPC is to directly utilize the inherent discrete characteristics and the switch state of power converter. It can also solve the introduced problems including torque ripple and large current harmonic in FCS-MPC in some ways $[9,11]$. These significant advantages make it a hot topic in the research of predictive control of power electronic system models, and it has to be the best alternative to traditional current loop based on PI regulator. Compared with the traditional vector control, FCS-MPC has the advantages of simpler control structure, excellent dynamic response, no need of current inner loop controller and no PWM modulator, it has developed rapidly in the field of motor speed regulation. This paper is based on the direct current control FCS-MPC method.

However, there are unavoidable challenges in MPC systems, when the model parameters are mismatched, the control effect will be ruined. MPC relies heavily on accurate IPMSM mathematical model, which means that the disturbance of motor parameters and the delay of the digital control system would deteriorate the tracking performance of the stator current [4], while the performance of current control is the key factor to the whole IPMSM control system. Many novel methods have been drawn out to solve the problems mentioned above. In $[18,19]$, a motor parameter disturbance compensation method based on sliding-model disturbance observer is presented, which can effectively improve the dynamic performance of stator currents and eliminate its steady-state error. However, the disadvantage is that the design process is complicated, the calculation amount is large, and the differentiation of the state variables is required in the calculation process, which leads to the amplification of the noise signal.

The various methods discussed above are based on parameters disturbance observation to solve the problem of poor robustness caused by parameters mismatch during the operation of motor control system. Moreover, the suppression of parameter disturbance and ability of reference current value tracking could be improved from the perspective of parameter identification. Off-line and online identification are two common types of parameter identification methods. The values of off-line parameter identification cannot track the changes of motor parameters in real time [20]. Compared with the off-line identification method, the online identification method of motor parameters not only estimates the state values of the motor in real time but also apply the values to the fault diagnosis method of the motor. For IPMSM, recursive least squares algorithm [21,22], model reference adaptive algorithm [23-25], extended Kalman filter algorithm [26,27], and neural network algorithm [28-31] are the most common online identification algorithms. The recursive least squares algorithm is often used in practice. Its structure is simple and unbiased estimation can be achieved. However, matrix calculation is 
complicated and difficult to realize. Kalman filtering algorithm can accurately observe the state variables and model parameters of the system and only requires low accuracy of input variables [26,27]. However, the algorithm is complex, and many intermediate variables need to be stored to meet the requirements of the algorithm, which requires high computing power of the processor. In [28,29], a dynamic learning estimator is proposed for tracking the electrical parameters of permanent magnet synchronous motor drive by using particle swarm optimization (PSO). However, the structure of PSO is complicated. In [32], a novel non-linear mapping-based feedback technique for controlling chaotic permanent magnet synchronous motor using dynamic surface control, neural approximation and parameter identification is proposed. In [33], a novel approach of speed control for a permanent magnet synchronous motor using on-line self-tuning artificial neural network is proposed. However, the algorithms used in $[32,33]$ are non-linear neural network, which requires a large amount of calculation. In [30,31], the permanent magnet flux linkage is estimated by an Adaline neural network. It is a linearly adjustable network, only contains simple addition, subtraction and multiplication calculations, so it is very suitable for parameter identification applications. However, in [30,31], only one parameter was identified based on Adaline neural network and the result had not applied in the motor vector control system. In order to improve the speed control performance of IPMSM system with the predictive current control strategy and MTPA method, this paper combines the parameter identification method with the MPC strategy, which can effectively suppress the effect caused by parameter perturbation. Due to the under-rank of the motor parameter identification matrix, the inductances and flux linkage of the motor cannot be estimated simultaneously. Thus, a step-by-step parameter identification method based on Adaline neural network is proposed to estimate parameters of IPMSM in this paper. And the results are applied into the FCS-MPC controller and MTPA model [34,35]. Finally, experimental results demonstrate that, compared with the traditional FCS-MPC algorithm, the proposed optimal FCS-MPC algorithm has better performance of steady-state current tracking.

The rest of this paper is organized as follows. In Section 2, the mathematical model of the IPMSM and analysis of the traditional model predictive current control based on MTPA are introduced. In Section 3, the design of optimal MPC method combined with Adaline neural network parameter identification is presented. In Section 4, the experimental results conducted on a digital control system is presented. In Section 5, the conclusion of this paper is presented.

\section{Predictive Control of IPMSM}

\subsection{Mathematical Model of the IPMSM}

The IPMSM is a multi-variable, non-linear and strongly coupled system. The voltage equations of IPMSM in synchronous rotating frame are shown in Equation (1) [36,37].

$$
\left\{\begin{array}{l}
u_{d}=R i_{d}+L_{d} \frac{d}{d t} i_{d}-\omega_{e} L_{q} i_{q} \\
u_{q}=R i_{q}+L_{q} \frac{d}{d t} i_{q}+\omega_{e}\left(L_{d} i_{d}+\psi_{f}\right)
\end{array}\right.
$$

where $i_{d}$ and $i_{q}$ are, respectively, the $\mathrm{d}$ - and q-axis currents; $u_{d}$ and $u_{q}$ are, respectively, the $\mathrm{d}$ - and q-axis stator voltages; $L_{d}$ and $L_{q}$ are, respectively, the d-and q-axis stator inductance of the stator windings; $R$ is the stator resistance; $\Psi_{f}$ is the permanent magnet flux linkage; and $\omega_{e}$ is rotor electrical angular velocity $(\mathrm{rad} / \mathrm{s})$.

The mechanical model of a IPMSM system can be expressed as follows:

$$
\begin{gathered}
T_{e}=\frac{3}{2} n_{p} i_{q}\left[i_{d}\left(L_{d}-L_{q}\right)+\psi_{f}\right] \\
J \frac{d \omega_{m}}{d t}=T_{e}-T_{L}-B \omega_{m}
\end{gathered}
$$


where $\omega_{m}$ is the rotor mechanical angular velocity, $J$ is the moment of inertia, $T_{e}$ is the electromagnetic torque, $T_{L}$ is the load torque, $B$ is the friction coefficient, $n_{p}$ is the number of pole pairs. The relation between the rotor mechanical angular velocity and rotor electrical angular velocity is given by:

$$
\omega_{e}=n_{p} \omega_{m}
$$

As for IPMSM, $L_{q}>L_{d}$ is valid, in order to minimize the output current while obtaining maximum electromagnetic torque; the MTPA control method is often used to effectively utilize the reluctance torque. The relationship between $i_{d}$ and $i_{q}$ is:

$$
i_{d}=\frac{\psi_{f}}{2\left(L_{q}-L_{d}\right)}-\sqrt{\frac{\psi_{f}^{2}}{4\left(L_{q}-L_{d}\right)^{2}}+i_{q}^{2}}
$$

Equations (2) and (5) indicate that both $i_{d}$ and $i_{q}$ are non-zero when the motor is operating on load. The discrete equations of the motor running in steady state from Equation (1) can be simplified as:

$$
\left\{\begin{array}{l}
u_{d}(k)=R i_{d}(k)-\omega_{e}(k) L_{q} i_{q}(k) \\
u_{q}(k)=R i_{q}(k)+\omega_{e}(k) L_{d} i_{d}(k)+\omega_{e}(k) \psi_{f}
\end{array}\right.
$$

where $k$ is the sampling moment.

The steady-state voltage equation of the motor is an under-ranking system with two equations and four unknown parameters $\left(R, L_{d}, L_{q}, \Psi_{f}\right)$. Since the back EMF generated by the stator winding can balance the supply voltage, the stator current produces a very small voltage drop across the winding resistance. Therefore, when the stator resistance changes, the influence on the system is very small. Moreover, if the stator resistance is estimated, the under-rank problem of the identification equation will be further increased. Therefore, ignoring the influence of the stator resistance, this paper only estimates the $d-q$ axis inductances and the rotor permanent magnet flux linkage. The step-by-step and cycle update method is used to estimate the motor parameters.

\subsection{Design of FCS-MPC for IPMSM}

By using a rotating $\mathrm{d}$-q reference frame oriented to the rotor magnetic field axis, a double loop of feedback has been adopted that makes control and scheduling better for synchronous designing and running. In this way, the machine control is implemented as a current control scheme, where the current references are generated by the external speed control loop. The model of the machine is used for predicting the behavior of the stator currents, and the cost function considers the error between the reference currents and predictive currents.

When the sampling period of control system is sufficiently short, the discrete time model of IPMSM can be obtained by a first-order Euler expansion, and the expressions of the stator current in the $\mathrm{d}-\mathrm{q}$ synchronous rotating frame can be described as Equation (7):

$$
\left\{\begin{array}{l}
i_{d}(k+1)=\left(1-\frac{R T_{s}}{L_{d}}\right) i_{d}(k)+\frac{L_{q} T_{s} \omega_{e}}{L_{d}} i_{q}(k)+\frac{T_{s}}{L_{d}} u_{d}(k) \\
i_{q}(k+1)=\left(1-\frac{R T_{s}}{L_{q}}\right) i_{q}(k)+\frac{L_{d} T_{s} \omega_{e}}{L_{q}} i_{d}(k)+\frac{T_{s}}{L_{q}} u_{q}(k)-\frac{\psi_{f} \omega_{e} T_{s}}{L_{q}}
\end{array}\right.
$$

where $T_{S}$ is the sampling period.

For the current predictive control strategy, the sum of the squared errors between $\mathrm{d}-\mathrm{q}$ axis predictive currents, and the reference current is usually used as a cost function, which can be described as Equation (8):

$$
g=\left|i_{\text {dref }}-i_{d}(k+1)\right|^{2}+\left|i_{q r e f}-i_{q}(k+1)\right|^{2}
$$

where $i d_{r e f}$ and $i q_{r e f}$ are the $\mathrm{d}$-axis and q-axis reference currents, and $i_{d}(k+1)$ and $i_{q}(k+1)$ are predicted current values of $\mathrm{d}-\mathrm{q}$ axis component of stator current at $k+1$ time period under given voltage vector. 
The block diagram of the FOC scheme of IPMSM using proposed FCS-MPC is shown in Figure 1. As shown in proposed method, the speed loop is controlled by a traditional PI controller, and accurate tracking of stator current is accomplished by FCS-MPC controller.

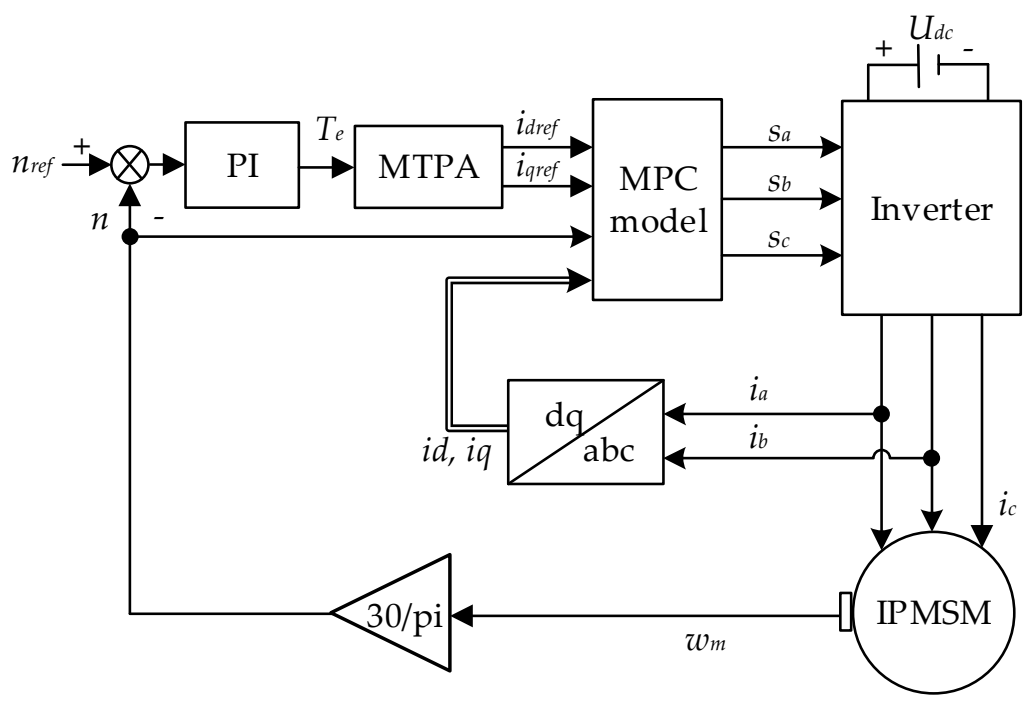

Figure 1. Control diagram of discrete state limited control set-model predictive control (FCS-MPC) for interior permanent magnet synchronous motor (IPMSM) drives.

Where, $i_{a}, i_{b}$, and $i_{c}$ are a-phase, b-phase, and c-phase stator currents, respectively, and the state definitions for each arm are as follows. $S_{a}, S_{b}$, and $S_{c}$ are the switching states of the three bridge arms, respectively. When the value of $S_{a}, S_{b}$, or $S_{c}$ is equal to 1 , the corresponding bridge arm is in the open state. Conversely, the bridge arm is in the close state when the value of $S_{a}, S_{b}$, or $S_{c}$ is equal to 0 .

When control schemes based on FCS-MPC are adopted, a large number of calculations are required, introducing a considerable time delay in the actuation. This delay will deteriorate the performance of the system if not considered in the design of the controller. A simple solution to compensate this delay is to take into account of the calculation time and apply the selected switching state after the next sampling instant. The model predictive control algorithm with delay compensation can be represented as the flowchart presented in Figure 2.

In Figure 2, $m$ is the intermediate variable, which is set to judge whether the system is sampling for the first time. When the system is initialized and started, $m=0$ is set. At this time, the system has not calculated the optimal voltage vector; zero voltage vector is applied, and $m=1$ is set. During the operation of the system, $m=1$ is kept, and the optimal voltage vector provided by the predictive controller can be applied. Moreover, $x$, from 1 to 8 , represents eight switch states of two-level inverter, namely, $000,001,010,011,100,101,110$, and 111 . When the upper bridge arm is turned on and the lower bridge arm is turned off, it is expressed as 1. Otherwise, when the upper bridge arm is turned off and the lower bridge arm is turned on, it is expressed as 0 .

The output voltages of the inverter, in PWM forms, cannot be measured directly. For the IPMSM vector control system based on traditional PI controller, the outputs of the PI controllers in current loop are usually approximated to the actual input voltages ud and uq of IPMSM. 


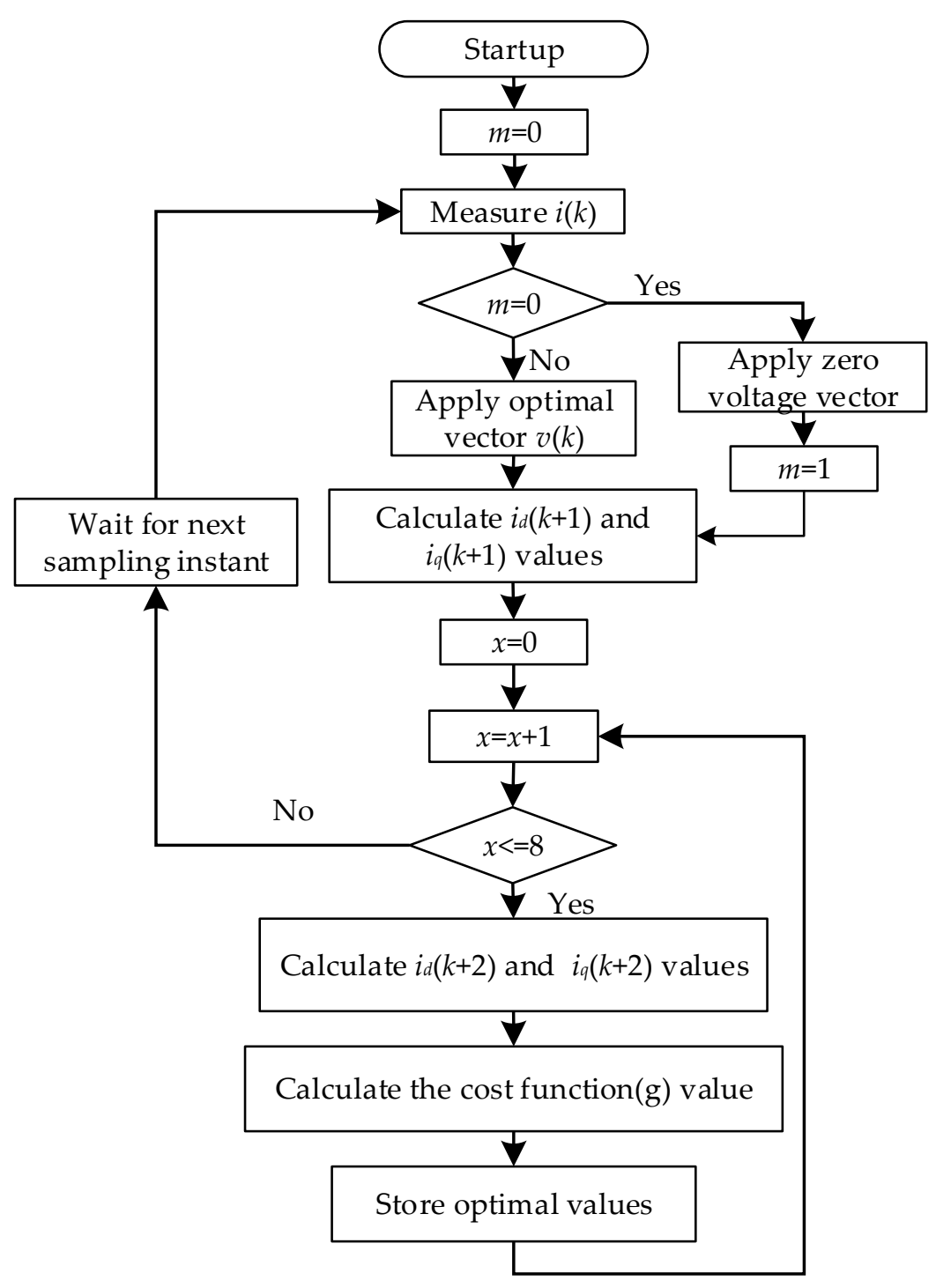

Figure 2. Flowchart of the predictive current control with delay compensation.

However, the traditional current PI controller is alternated by FCS-MPC controller in IPMSM predictive control system. In order to obtain the effective values of $u_{d}$ and $u_{q}$, it can be reconstructed by DC bus voltage $U_{d c}$, inverter switching state, and rotor position electrical angle $\theta$. The equation is shown in Equation (9):

$$
\left\{\begin{array}{l}
U_{A N}=\frac{U_{d c}}{3}\left(2 S_{a}-S_{b}-S_{c}\right) \\
U_{B N}=\frac{U_{d c}}{3}\left(2 S_{b}-S_{a}-S_{c}\right) \\
U_{C N}=\frac{U_{d c}}{3}\left(2 S_{c}-S_{a}-S_{b}\right) \\
u_{d}=\frac{2}{3}\left(U_{A N} \cos \theta+U_{B N} \cos \left(\theta-\frac{2 \pi}{3}\right)+U_{C N} \cos \left(\theta+\frac{2 \pi}{3}\right)\right) \\
u_{q}=\frac{2}{3}\left(-U_{A N} \sin \theta+U_{B N} \sin \left(\theta-\frac{2 \pi}{3}\right)+U_{C N} \sin \left(\theta+\frac{2 \pi}{3}\right)\right)
\end{array}\right.
$$

where $U_{A N}, U_{B N}$, and $U_{C N}$ are the phase-to-neutral voltage of the inverter. $U_{d c}$ is DC bus voltage, and $\theta$ is the rotor position electrical angle.

However, the values of $u_{d}$ and $u_{q}$, obtained from Equation (7), are in the PWM forms, which contain large numbers of high-order harmonics and cannot be used in parameter identification algorithm. An effective solution to obtain the effective values of $u d$ and uq of the inverter is to make the voltages pass through low-pass filters. 


\section{FCS-MPC of IPMSM Based on Parameter Identification}

\subsection{Online Parameter Identification Strategy}

In order to identify the d-axis inductance, q-axis inductance and rotor permanent magnet flux linkage of IPMSM simultaneously, the rank of the identification coefficient matrix of motor parameters must be greater than or equal to three. However, the maximum rank of the coefficient matrix of the steady-state operation of the motor is two. Two methods are usually adopted to solve the under-rank problem. The first is to obtain the multi-group operation state of the motor by injecting current signal, thereby increasing the rank of identification equations. The second is to divide the parameter identification system into different parts and identify them alternately. However, the first method has some limitations; a fixed current vector will be generated in the motor, which will cause torque ripple, affecting the control accuracy and running quality of the system. The identification accuracy is also heavily dependent on the quality of the injected current signal.

With the MTPA control method, when the motor is running in steady state, Equation (1) is rewritten as the following matrix form:

$$
\left[\begin{array}{c}
u_{d}(k)-R i_{d}(k) \\
u_{q}(k)-R i_{q}(k)
\end{array}\right]=\left[\begin{array}{ccc}
0 & -\omega_{e}(k) i_{q}(k) & 0 \\
\omega_{e}(k) i_{d}(k) & 0 & \omega_{e}(k)
\end{array}\right]\left[\begin{array}{c}
L_{d} \\
L_{q} \\
\psi_{f}
\end{array}\right]
$$

$\Phi$ is defined as the coefficient matrix of motor parameter identification.

$$
\phi=\left[\begin{array}{ccc}
0 & -\omega_{e}(k) i_{q}(k) & 0 \\
\omega_{e}(k) i_{d}(k) & 0 & \omega_{e}(k)
\end{array}\right]
$$

The first and third columns of matrix $\Phi$ are linearly correlated. Therefore, it is impossible to identify the $d-q$ axis inductances and permanent magnet flux linkage of IPMSM simultaneously. In order to solve the above problem, the parameters of the motor were estimated by the step-by-step identification strategy in this paper.

Through the above analysis, the IPMSM motor parameters can be identified by step-by-step identification strategy proposed in this paper. Considering the under-rank problem of the motor parameter identification matrix, the motor parameters are usually divided into several groups depending on the motor parameters' changing speed, in which a part of the motor parameters are set to known values, and then, the parameter identification algorithm is used to estimate the remaining parameters. Based on the identification result, the original set parameters values are identified in the next step, so that all parameters of the motor can be identified and cyclically updated by the method proposed in this paper.

\subsection{Adaline Neural Network Identification Method}

In this paper, the Adaline neural network algorithm is used to identify the motor parameters. It is a linearly adjustable network, which is very similar to the single layer perceptron [38], except that the functions of creating neural networks are different. It has the characteristics that the network weight and threshold can be directly obtained by using the design function without training, and the output of the network layer can take any value, overcoming disadvantages of the output of the perceptron neural network which can only be 0 or 1 . Therefore, it is suitable for the fields of adaptive filtering, prediction and model recognition in signal processing. By observing its excitation function and weight function, we can find that its expression only contains simple addition, subtraction, and multiplication calculations and does not contain matrix calculation or division calculation. The calculation amount is small, and there is only one adjustable parameter (step size), which makes it easy to adjust compared with nonlinear neural network $[32,33]$. Combining the above advantages, the Adaline neural network identification method is selected in this paper. 
The principle of parameter identification of Adaline neural network is as follows:

First, the network structure matching the control system is selected, and the input variables are taken into the neural network identifier. Then, according to the output error between the identification system output and the network output, combined with the weight convergence algorithm, the network weight correction is performed to realize the online parameter identification.

The structure diagram of Adaline neural network is as follows in Figure 3:

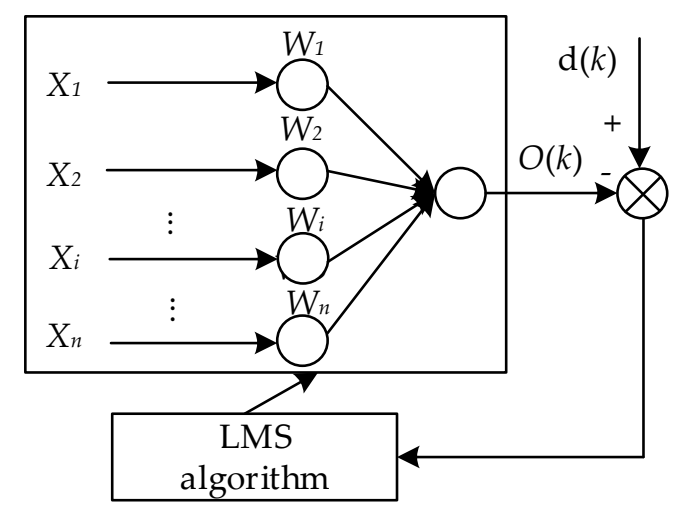

Figure 3. The structure of Adaline neural network.

Its excitation function is:

$$
O\left(W_{i}, X_{i}\right)=\sum_{i=0}^{n} W_{i} X_{i}
$$

where $W_{i}$ is the weight of the neural network, $X_{i}$ is the network input signal, and $O\left(W_{i}, X_{i}\right)$ is the output of excitation function of the network.

The weight adjustment algorithm of the network when the least mean square (LMS) algorithm is used is:

$$
\left\{\begin{array}{l}
W_{i}(k+1)=W_{i}(k)+2 \eta X_{i} \varepsilon(k) \\
\varepsilon(k)=d(k)-O(k)
\end{array}\right.
$$

where $d(k)$ is the network target output, $\eta$ is the weight adjustment size, and $\varepsilon(k)$ is the error between the neural network output and the target output.

When the motor parameters are estimated by the Adaline neural network algorithm, $L_{d}, L_{q}$, and $\Psi_{f}$ are regarded as the weights of the network, and the values of the motor parameters can be obtained by weight calculation. In order to ensure the convergence of the algorithm, $\eta$ in Equation (13) needs to satisfy the following relationship [31]:

$$
0<2 \eta|X(k)|^{2}<1
$$

In the above algorithm, the real gradient is replaced by the estimated gradient. The correlation matrix and the inverse matrix are not needed, which makes the computation speed faster. When the convergence factor is selected properly, the stability and rapidity of the identification system can be guaranteed simultaneously.

In this paper, an on-line parameter identification method of IPMSM based on Adaline neural network is proposed. The motor parameters are identified in four steps. First, when the motor rotor is in a static state, the stator resistance is measured by injecting d-axis current. Second, when the motor is started, the resistance value in the voltage equation is set to static measurement value, and the q-axis inductance is estimated. Third, the permanent magnet flux linkage and the $\mathrm{d}$-axis inductance are identified. Finally, the motor parameters are cyclically updated. It is assumed that the stator resistance remains constant. According to the motor torque equation, d-axis inductance, $\mathrm{q}$-axis inductance, 
and rotor flux linkage of IPMSM can be obtained, respectively. The identification equations are as follows:

$$
\begin{gathered}
\left\{\begin{array}{l}
X_{L_{q}}(k)=-\omega_{e}(k) i_{q}(k) \\
O_{L_{q}}(k)=L_{q}(k) X_{L_{q}}(k) \\
d_{L_{q}}(k)=U_{d}(k)-R i_{d}(k) \\
L_{q}(k+1)=L_{q}(k)+2 \eta_{L_{q}} X_{L_{q}}(k) \varepsilon_{L_{q}}(k)
\end{array}\right. \\
\left\{\begin{array}{l}
X_{L_{d}}(k)=\omega_{e}(k) i_{d}(k) \\
O_{L_{d}}(k)=L_{d}(k) X_{L_{d}}(k) \\
d_{L_{d}}(k)=U_{q}(k)-\omega_{e}(k) \psi_{f}-R i_{q}(k) \\
L_{d}(k+1)=L_{d}(k)+2 \eta_{L_{d}} X_{L_{d}}(k) \varepsilon_{L_{d}}(k)
\end{array}\right. \\
\left\{\begin{array}{l}
X_{\psi_{f}}(k)=\omega_{e}(k) \\
O_{\psi_{f}}(k)=\psi_{f}(k) X_{\psi_{f}}(k) \\
d_{\psi_{f}}(k)=U_{q}(k)-R i_{q}(k)-\omega_{e}(k) L_{d} i_{d}(k) \\
\psi_{f}(k+1)=\psi_{f}(k)+2 \eta_{\psi_{f}} X_{\psi_{f}}(k) \varepsilon_{\psi_{f}}(k)
\end{array}\right.
\end{gathered}
$$

where, $U_{d}$ and $U_{q}$ are the effective values of ud and uq.

The model predictive control block diagram of IPMSM based on parameter identification with Adaline neural network is shown in Figure 4.

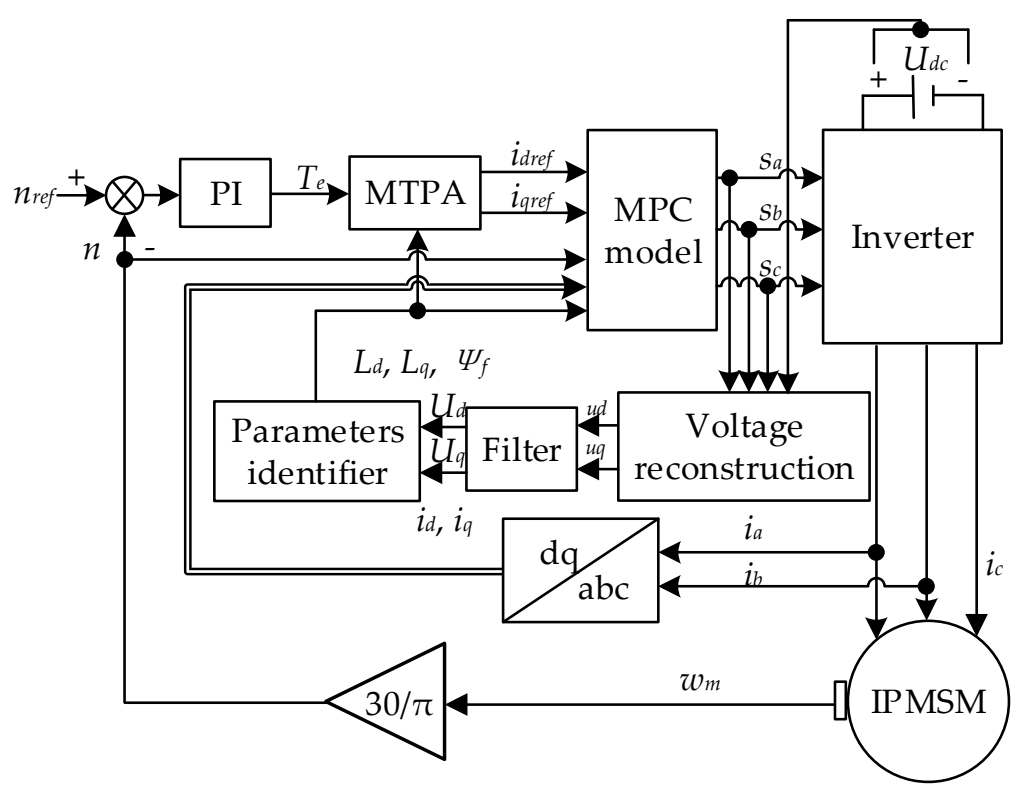

Figure 4. Block diagram of IPMSM parameter identification based on FCS-MPC.

\section{Experimental Results Analysis}

In order to verify the effectiveness of the model predictive control algorithm based on parameter identification mentioned in this paper, an experimental platform is built based on TI 2812 DSP chip (Texas Instruments, Dallas, USA) for experiment. The parameters of the IPMSM motor are listed in Table 1. In the practical experiment, the crude estimation values are defined as the true parameters of $\operatorname{IPMSM}\left(L_{d 0}, L_{q 0}\right.$, and $\left.\Psi_{f 0}\right)$, which are utilized for experiments under parameter mismatch conditions. 
Table 1. Parameters of the IPMSM.

\begin{tabular}{ll}
\hline Parameter & Value \\
\hline Armature resistance & $0.1 \Omega$ \\
d-axis inductance & $0.95 \mathrm{mH}$ \\
q-axis inductance & $2.05 \mathrm{mH}$ \\
Flux linkage & $0.225 \mathrm{~Wb}$ \\
Pole pairs & 4 \\
Rated power & $60 \mathrm{~kW}$ \\
\hline
\end{tabular}

The experimental platform is constructed by TI processor, which is mainly composed of two IPMSMs, one rectifier, two inverters, and three controllers. The experimental platform is shown in Figure 5. Sampling frequency of the control system is set to $10 \mathrm{kHz}$, and the speed reference is $900 \mathrm{rpm}$. A rotary decoder is employed to obtain the position and speed of the motor rotor. In order to verify the effectiveness of the method at variable load, the load torque of $40 \mathrm{Nm}$ and $30 \mathrm{Nm}$ are suddenly added at times $\mathrm{c}$ and $\mathrm{d}$.
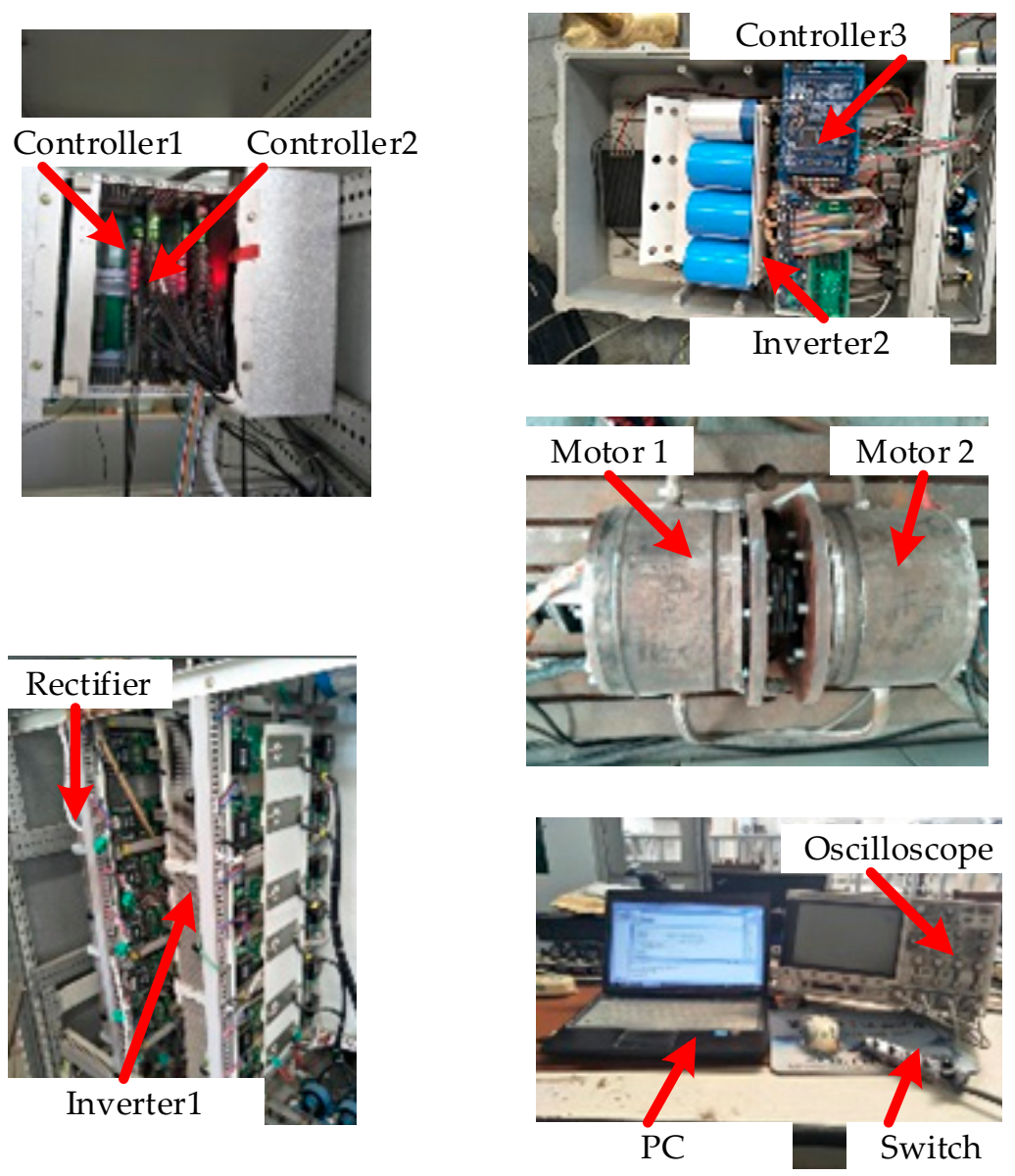

Figure 5. The experimental platform.

The experiment was conducted in three parts. The experimental results of current references and current responses with different parameter mismatch are shown in Figures 6-11. The orange and blue lines represent the $\mathrm{d}$-axis current and q-axis current reference values respectively. The green line and the red line represent the current response values of $d$-axis and q-axis respectively. As can be seen from Figures 6-11, when the parameters are mismatched, the error between the predictive current and the current reference value increases, and the control effect is seriously disturbed. The reason why the control effect is disturbed is that the control performance of IPMSM controlled by FCS-MPC is 
heavily dependent on the motor parameters. When the motor parameters do not match the motor parameters in the controller, the deviation between the reference current and the response current will occur. More importantly, the parameter mismatch causes significant response current fluctuations, which will have a bad impact on the control performance of the control system.

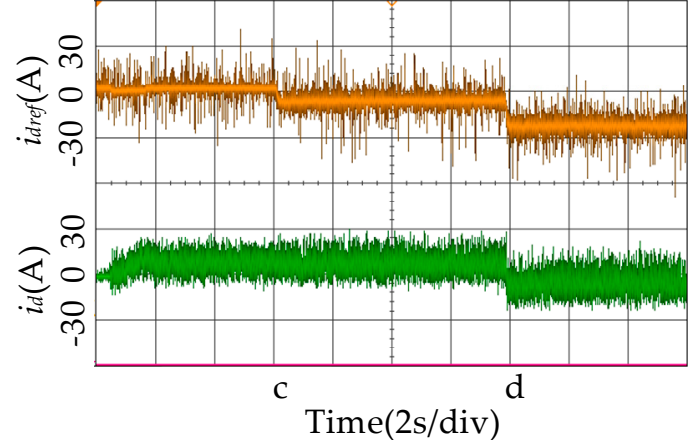

(a)

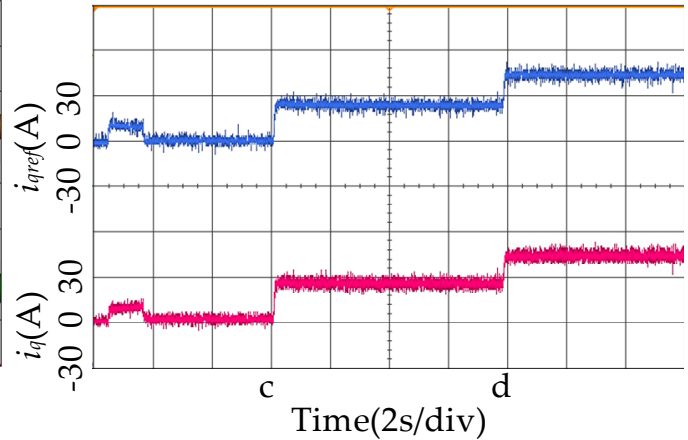

(b)

Figure 6. Experimental results of MPC under $L_{d}=2 L_{d 0}$. (a) d-axis current reference and its response. (b) q-axis current reference and its response.

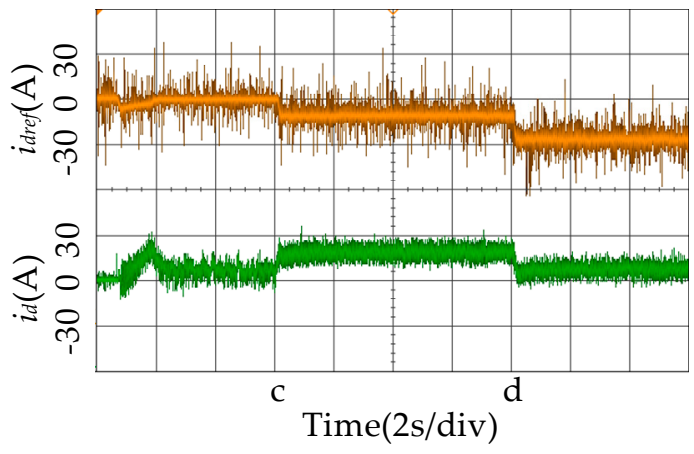

(a)

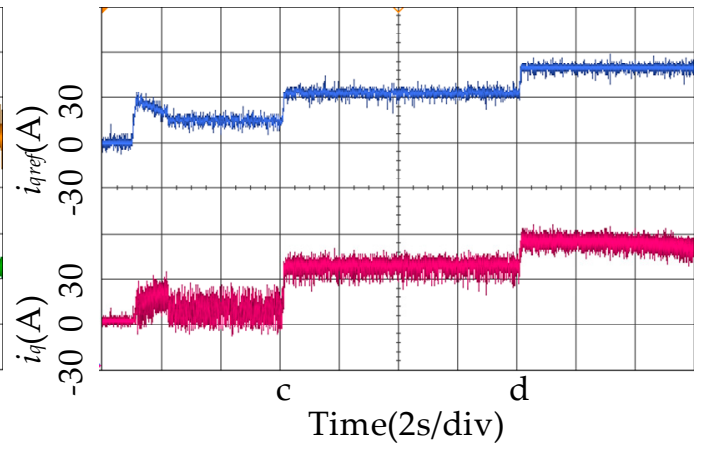

(b)

Figure 7. Experimental results of MPC under $L_{d}=0.5 L_{d 0}$. (a) d-axis current reference and its response. (b) q-axis current reference and its response.

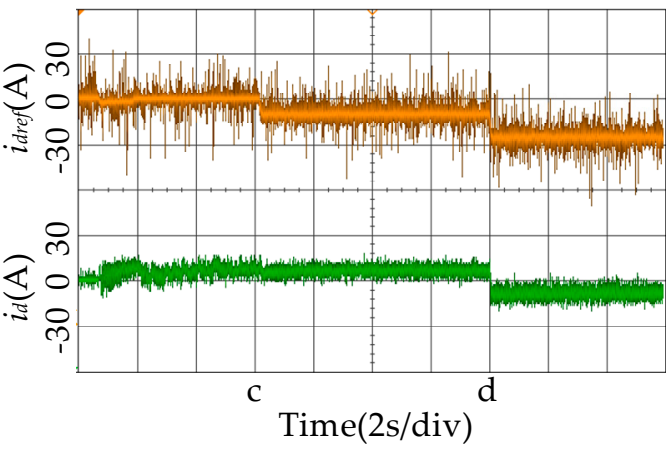

(a)

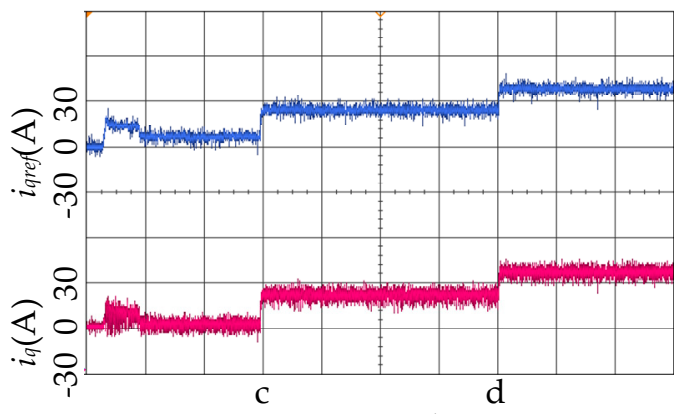

Time(2s/div)

(b)

Figure 8. Experimental results of MPC under $L_{q}=2 L_{q 0}$. (a) d-axis current reference and its response. (b) q-axis current reference and its response. 


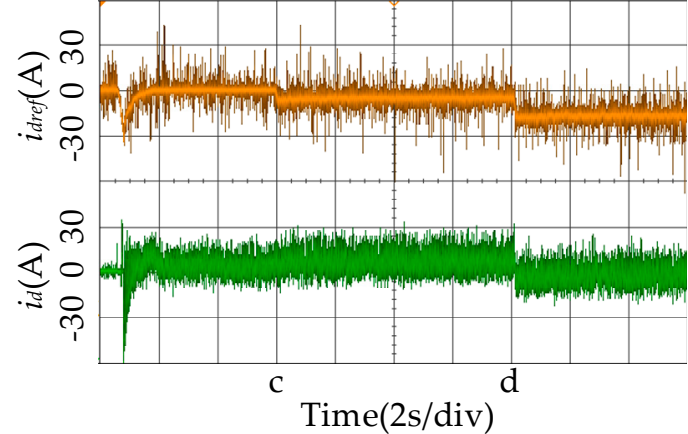

(a)

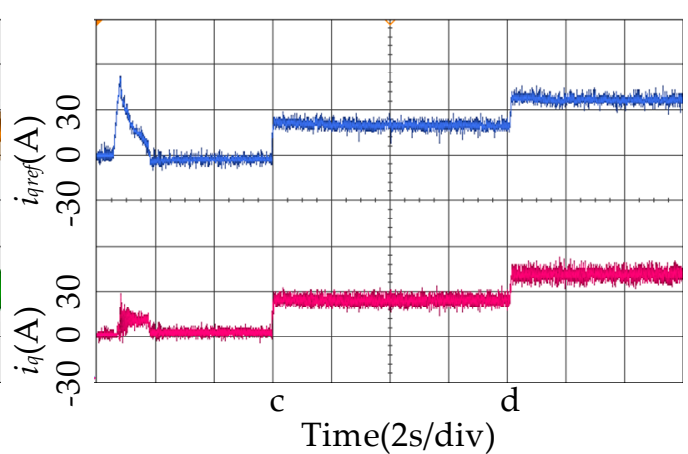

(b)

Figure 9. Experimental results of MPC under $L_{q}=0.5 L_{q 0}$. (a) d-axis current reference and its response. (b) q-axis current reference and its response.

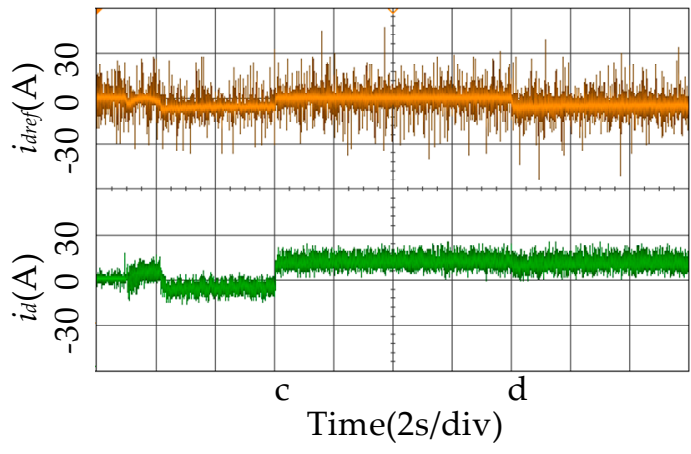

(a)

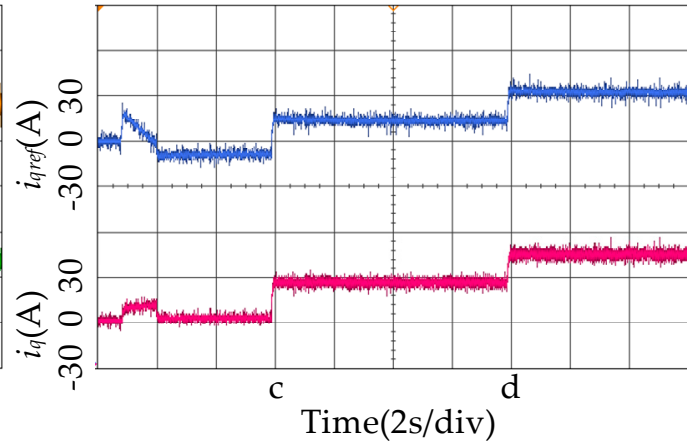

(b)

Figure 10. Experimental results of MPC under $\Psi_{f}=2 \Psi_{f 0}$. (a) d-axis current reference and its response. (b) q-axis current reference and its response.

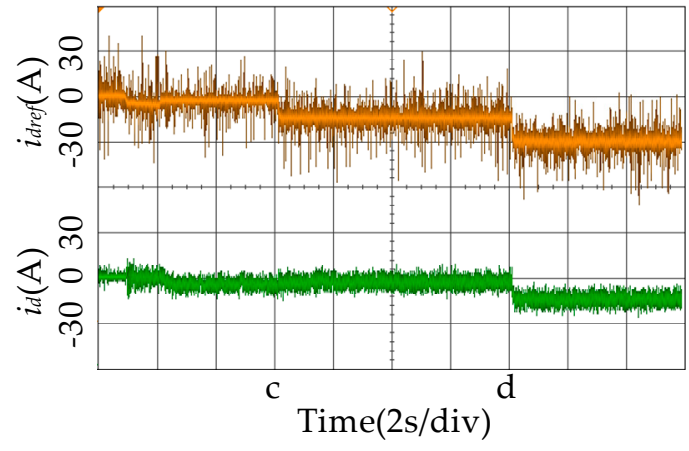

(a)

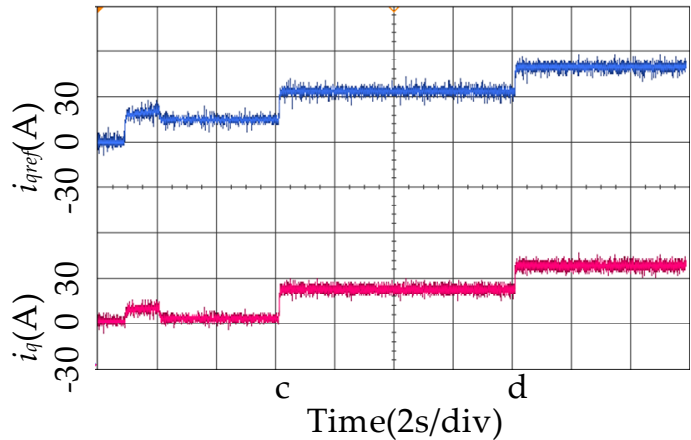

(b)

Figure 11. Experimental results of MPC under $\Psi_{f}=0.5 \Psi_{f 0}$. (a) d-axis current reference and its response. (b) q-axis current reference and its response.

Afterwards, the result of the IPMSM parameters identification based on the FCS-MPC and Adaline neural network algorithm was verified. Figure 12 shows the identification result of the $d-q$ axis inductances and the rotor permanent magnet flux, where the d-axis inductance is represented by orange line, the q-axis inductance is represented by red line, and the rotor permanent magnet flux linkage is represented by blue line. It can be seen from the figure that the motor parameters can be quickly and accurately estimated in real time by the algorithm proposed in this paper so that the identification values can be applied to the FCS-MPC controller. 


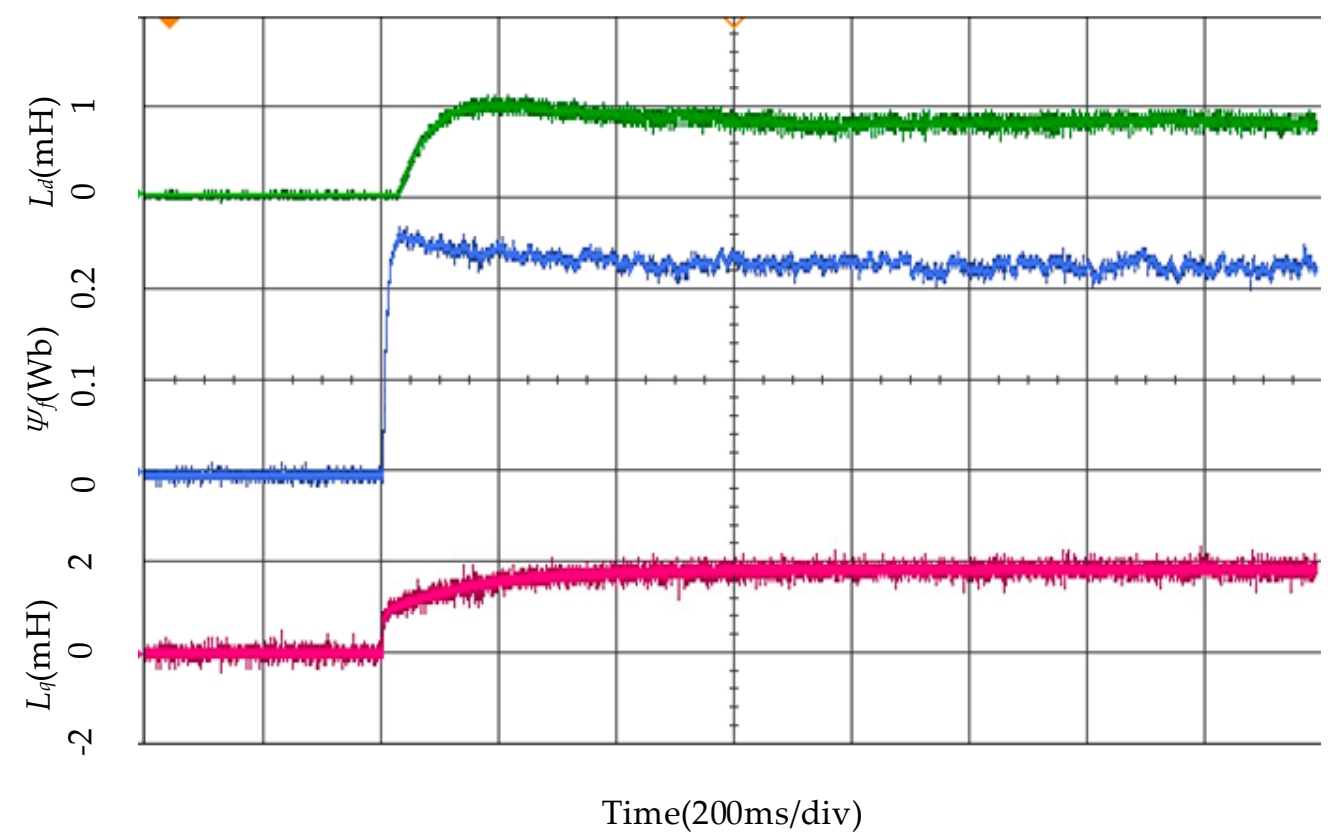

Figure 12. Experimental results of $\mathrm{d}-\mathrm{q}$ axis inductances and rotor permanent magnet flux linkage identification.

Finally, the experimental results of current references and current responses with MPC based on Adaline parameter identification method are shown in Figure 13. The orange and blue lines represent the d-axis current and q-axis current reference values, respectively. The green line and the red line represent the current response values of $d$-axis and q-axis, respectively. Comparing with the parameters mismatch condition, it can be found that in this case the $\mathrm{d}$-q axis, current responses can track the current references better and significantly reduce the errors between them. The reason is that during the operation of the motor, the motor parameters can be estimated effectively, and the controller parameters can be adjusted as well, which can effectively improve the current control effect even under the changing load operating state.

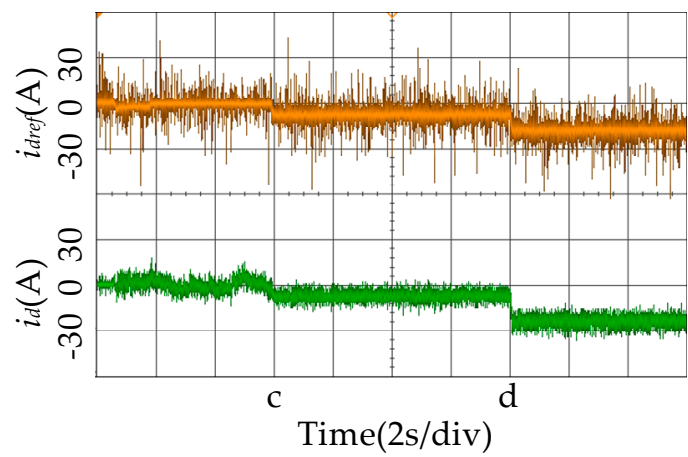

(a)

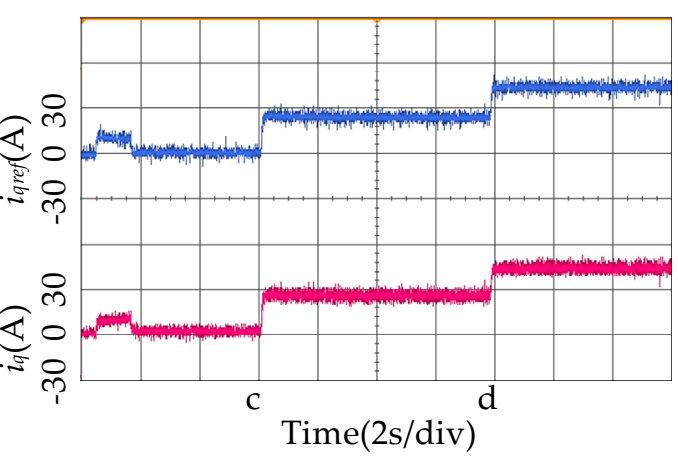

(b)

Figure 13. Experimental results of predictive control for IPMSM based on parameter identification with Adaline neural network method. (a) d-axis current reference and its response. (b) q-axis current reference and its response.

From the analysis of the experimental waveform, it can be known that the disturbance of motor parameters can deteriorate the performance of IPMSM operating based on FCS-MPC control strategy with MTPA method. The accuracy of steady-state tracking of the d-q axis currents are affected by the values of IPMSM parameters. By adopting the proposed optimal MPC method based on Adaline neural 
network algorithm in this paper, the d-q axis current static error can be eliminated in the presence of parameters disturbance.

\section{Conclusions}

In this paper, a novel online parameter identification method based on Adaline linear neural network for IPMSM is proposed. The discrete time model of IPMSM is derived and the traditional FCS-MPC algorithm is figured out based on this discrete time model. The experimental results show that the traditional FCS-MPC method is sensitive to parameter disturbance such as $\mathrm{d}-\mathrm{q}$ axis inductances and flux linkage of permanent magnet. In the proposed optimal MPC method, the inductance and flux linkage parameters are identified based on Adaline neural network in real time and then applied to FCS-MPC controller and MTPA module. The experimental results show that the proposed optimal algorithm can suppress the influence caused by parameters disturbance and improve the system's performance of steady-state current tracking.

Author Contributions: L.W. proposed the new scheme. L.W. and J.M. performed the experiments and data analysis. L.W. wrote the first draft, and G.T. and J.M. guided and revised the manuscript.

Funding: The project is supported by the National Natural Science Foundational of China (Grant number: U1610113) and National Key R\&D Program of China (Grant number: 2016YFC0600804).

Conflicts of Interest: The authors declare no conflict of interest.

\section{References}

1. Inoue, Y.; Yamada, K.; Morimoto, S.; Sanada, M. Effectiveness of Voltage Error Compensation and Parameter Identification for Model-Based Sensorless Control of IPMSM. IEEE Trans. Ind. Appl. 2009, 45, 213-221. [CrossRef]

2. Wang, Q.; Niu, S.; Ching, T.W. A New Double-Winding Vernier Permanent Magnet Wind Power Generator for Hybrid AC/DC Microgrid Application. IEEE Trans. Magn. 2018, 54, 1-5. [CrossRef]

3. Niu, L.; Xu, D.; Yang, M.; Gui, X.; Liu, Z. On-line Inertia Identification Algorithm for PI Parameters Optimization in Speed Loop. IEEE Trans. Power Electron. 2015, 30, 849-859. [CrossRef]

4. Guo, X.; Du, S.; Li, Z.; Chen, F.; Chen, K.; Chen, R. Analysis of Current Predictive Control Algorithm for Permanent Magnet Synchronous Motor Based on Three-Level Inverters. IEEE Access 2019, 7, 87750-87759. [CrossRef]

5. Niu, L.; Yang, M.; Xu, D. Predictive current control for Permanent Magnet Synchronous Motor based on deadbeat control. In Proceedings of the 2012 7th IEEE Conference on Industrial Electronics and Applications (ICIEA), Singapore, 18-20 July 2012; pp. 46-51.

6. Slotine, J.-J.E.; Li, W. Applied Nonlinear Control; Prentice-Hall Englewood Cliffs: Upper Saddle River, NJ, USA, 1991; Volume 199.

7. Du, H.; Hu, X.; Ma, C.; Zhang, G. Numerical PI tuning method and its application in aircraft pitch control. In Proceedings of the 2017 12th IEEE Conference on Industrial Electronics and Applications (ICIEA), Siem Reap, Cambodia, 18-20 June 2017; pp. 1270-1274.

8. Silva, G.J.; Datta, A.; Bhattacharyya, S.P. PID Controllers for Time-Delay Systems; Birkhauser: Basel, Switzerland; Berlin, Germany; Boston, MA, USA, 2005.

9. Liu, J.; Li, H.; Deng, Y. Torque Ripple Minimization of PMSM Based on Robust ILC Via Adaptive Sliding Mode Control. IEEE Trans. Power Electron. 2018, 33, 3655-3671. [CrossRef]

10. Zhang, X.; Sun, L.; Zhao, K.; Sun, L. Nonlinear Speed Control for PMSM System Using Sliding-Mode Control and Disturbance Compensation Techniques. IEEE Trans. Power Electron. 2013, 28, 1358-1365. [CrossRef]

11. Wang, W.; Fan, Y.; Chen, S.; Zhang, Q. Finite control set model predictive current control of a five-phase PMSM with virtual voltage vectors and adaptive control set. CES Trans. Electr. Mach. Syst. 2018, 2, 136-141.

12. El-Sousy, F.F.M. Intelligent Optimal Recurrent Wavelet Elman Neural Network Control System for Permanent-Magnet Synchronous Motor Servo Drive. IEEE Trans. Ind. Inform. 2013, 9, 1986-2003. [CrossRef]

13. Lin, F.; Hung, Y.; Ruan, K. An Intelligent Second-Order Sliding-Mode Control for an Electric Power Steering System Using a Wavelet Fuzzy Neural Network. IEEE Trans. Fuzzy Syst. 2014, 22, 1598-1611. [CrossRef] 
14. NNalakath, S.; Sun, Y.; Preindl, M.; Emadi, A. Optimization-Based Position Sensorless Finite Control Set Model Predictive Control for IPMSMs. IEEE Trans. Power Electron. 2018, 33, 8672-8682. [CrossRef]

15. Mwasilu, F.; Nguyen, H.T.; Choi, H.H.; Jung, J. Finite Set Model Predictive Control of Interior PM Synchronous Motor Drives with an External Disturbance Rejection Technique. IEEE/ASME Trans. Mechatron. 2017, 22, 762-773. [CrossRef]

16. Mwasilu, F.; Kim, E.; Rafaq, M.S.; Jung, J. Finite-Set Model Predictive Control Scheme with an Optimal Switching Voltage Vector Technique for High-Performance IPMSM Drive Applications. IEEE Trans. Ind. Inform. 2017, 14, 3840-3848. [CrossRef]

17. Wang, W.; Liu, T.; Syaifudin, Y. Model Predictive Controller for a Micro-PMSM-Based Five-Finger Control System. IEEE Trans. Ind. Electron. 2016, 63, 3666-3676. [CrossRef]

18. Zhang, X.; Hou, B.; Mei, Y. Deadbeat Predictive Current Control of Permanent-Magnet Synchronous Motors with Stator Current and Disturbance Observer. IEEE Trans. Power Electron. 2017, 32, 3818-3834. [CrossRef]

19. Jiang, Y.; Xu, W.; Mu, C.; Liu, Y. Improved Deadbeat Predictive Current Control Combined Sliding Mode Strategy for PMSM Drive System. IEEE Trans. Veh. Technol. 2018, 67, 251-263. [CrossRef]

20. Du, X.; Zhang, W. High Precision Off-line Parameters Identification of PMSM Considering Dead-time Effect. In Proceedings of the 2019 IEEE 28th International Symposium on Industrial Electronics (ISIE), Vancouver, BC, Canada, 12-14 June 2019; pp. 336-341.

21. Underwood, S.J.; Husain, I. Online Parameter Estimation and Adaptive Control of Permanent-Magnet Synchronous Machines. IEEE Trans. Ind. Electron. 2010, 57, 2435-2443. [CrossRef]

22. Morimoto, S.; Sanada, M.; Takeda, Y. Mechanical Sensorless Drives of IPMSM with Online Parameter Identification. IEEE Trans. Ind. Appl. 2006, 42, 1241-1248. [CrossRef]

23. Kivanc, O.C.; Ozturk, S.B. Sensorless PMSM Drive Based on Stator Feedforward Voltage Estimation Improved with MRAS Multiparameter Estimation. IEEE/ASME Trans. Mechatron. 2018, 23, 1326-1337. [CrossRef]

24. Boileau, T.; Leboeuf, N.; Nahid-Mobarakeh, B.; Meibody-Tabar, F. Online Identification of PMSM Parameters: Parameter Identifiability and Estimator Comparative Study. IEEE Trans. Ind. Appl. 2011, 47, 1944-1957. [CrossRef]

25. Dezza, F.C.; Foglia, G.; Iacchetti, M.F.; Perini, R. An MRAS Observer for Sensorless DFIM Drives with Direct Estimation of the Torque and Flux Rotor Current Components. IEEE Trans. Power Electron. 2012, 27, 2576-2584. [CrossRef]

26. Shi, Y.; Sun, K.; Huang, H.M.L. Permanent magnet flux identification of IPMSM based on EKF with speed sensorless control. In Proceedings of the IECON 2010-36th Annual Conference on IEEE Industrial Electronics Society, Glendale, AZ, USA, 7-10 November 2010; pp. 2252-2257.

27. Shi, Y.; Sun, K.; Huang, L.; Li, Y. Online Identification of Permanent Magnet Flux Based on Extended Kalman Filter for IPMSM Drive with Position Sensorless Control. IEEE Trans. Ind. Electron. 2012, 59, 4169-4178. [CrossRef]

28. Liu, Z.; Wei, H.; Zhong, Q.; Liu, K.; Xiao, X.; Wu, L. Parameter Estimation for VSI-Fed PMSM Based on a Dynamic PSO with Learning Strategies. IEEE Trans. Power Electron. 2017, 32, 3154-3165. [CrossRef]

29. Liu, Z.; Wei, H.; Li, X.; Liu, K.; Zhong, Q. Global Identification of Electrical and Mechanical Parameters in PMSM Drive Based on Dynamic Self-Learning PSO. IEEE Trans. Power Electron. 2018, 33, 10858-10871. [CrossRef]

30. Liu, K.; Zhu, Z.Q. Online Estimation of the Rotor Flux Linkage and Voltage-Source Inverter Nonlinearity in Permanent Magnet Synchronous Machine Drives. IEEE Trans. Power Electron. 2014, 29, 418-427. [CrossRef]

31. Liu, K.; Zhu, Z.Q. Position-Offset-Based Parameter Estimation Using the Adaline NN for Condition Monitoring of Permanent-Magnet Synchronous Machines. IEEE Trans. Ind. Electron. 2015, 62, 2372-2383. [CrossRef]

32. Gao, S.; Dong, H.; Ning, B.; Tang, T.; Li, Y. Nonlinear mapping-based feedback technique of dynamic surface control for the chaotic PMSM using neural approximation and parameter identification. IET Control Theory Appl. 2018, 12, 819-827. [CrossRef]

33. Becerra, V.M.; Garces, F.R.; Nasuto, S.J.; Holderbaum, W. An efficient parameterization of dynamic neural networks for nonlinear system identification. IEEE Trans. Neural Netw. 2005, 16, 983-988. [CrossRef]

34. Li, K.; Wang, Y. Maximum Torque Per Ampere (MTPA) Control for IPMSM Drives Based on a Variable-Equivalent-Parameter MTPA Control Law. IEEE Trans Power Electron. 2019, 34, 7092-7102. [CrossRef] 
35. Li, K.; Wang, Y. Maximum Torque per Ampere (MTPA) Control for IPMSM Drives Using Signal Injection and an MTPA Control Law. IEEE Trans. Ind. Inform. 2019, 15, 5588-5598. [CrossRef]

36. Alexandrou, D.; Adamopoulos, N.K.; Kladas, A.G. Development of a Constant Switching Frequency Deadbeat Predictive Control Technique for Field-Oriented Synchronous Permanent-Magnet Motor Drive. IEEE Trans. Ind. Electron. 2016, 63, 5167-5175. [CrossRef]

37. Bode, G.H.; Loh, P.C.; Newman, M.J.; Holmes, D.G. An improved robust predictive current regulation algorithm. IEEE Trans. Ind. Appl. 2005, 41, 1720-1733. [CrossRef]

38. Gas, B. Self-Organizing MultiLayer Perceptron. IEEE Trans. Neural Netw. 2010, 21, 1766-1779. [CrossRef]

(C) 2019 by the authors. Licensee MDPI, Basel, Switzerland. This article is an open access article distributed under the terms and conditions of the Creative Commons Attribution (CC BY) license (http://creativecommons.org/licenses/by/4.0/). 